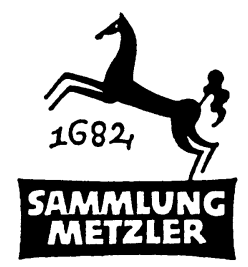

REALIENBUCHER ZUR LITERATUR

ABT D:

LITERATURGESCHICHTE 
HANS-ALBRECHT KOCH

\section{Das deutsche Singspiel}

MCMLXXIV

J. B. METZLERSCHE VERLAGSBUCHHANDLUNG STUTTGART 
IN PATRIS MEMORIAM

ISBN 978-3-476-10133-4

ISBN 978-3-476-03846-3 (eBook)

DOI 10.1007/978-3-476-03846-3

\section{I33}

(C) Springer-Verlag GmbH Deutschland 1974 Ursprünglich erschienen bei J. B. Metzlersche Verlagsbuchhandlung und Carl Ernst Poeschel Verlag GmbH in Stuttgart 1974 


\section{INHALT}

\section{Voraussetzungen}

I. Musik und Drama. Die Singspiele der englischen Komödianten . . . . . . . . . . . . . I

2. Commedia dell'arte, Théâtre italien, Komödie . . . 8

3. Oper ................... I6

II. Singspiel und Singspielforschung . . . . . . . . . . 24

III. Die Operette von Weisse und Hiller und ihren Nachfolgern . . . . . . . . . . . . . . . . 44

IV. Exkurs: Wielands Singspiele und die deutsche Oper . . 59

V. Das Singspiel in Süddeutschland . . . . . . . . . 62

VI. Wiener Komödie und Wiener Singspiel

I. Die Anfänge . . . . . . . . . . . . . . . . 66

2. Das Wiener Singspiel . . . . . . . . . . . 7I

3. Ausläufer des Wiener Singspiels. Operette . . . . 79

VII. Exkurs: Singspiel und Posse im Deutschen Orden . . . 85

VIII. Die Singspiele Goethes und ihre Vertonungen . . . . 87

IX. Das Singspiel der Romantik . . . . . . . . . . . 96

Nachträge ................. ro2

Register..................... . I03 


\section{VORWORT}

Der vorliegende Realienband behandelt das deutsche Singspiel, das als bürgerliche Unterhaltungsform im 18 . Jahrhundert zu weiter Verbreitung und großer Beliebtheit gelangt ist und als Vorläufer neuerer Unterhaltungsformen wie der Operette und des Musical gelten kann.

$\mathrm{Zu}$ einer Monographie über das deutsche Singspiel fehlt es heute weithin noch an den wichtigsten Voraussetzungen, an der Aufarbeitung der Quellen, an dem notwendigen Zusammenwirken von Musik-, Theater- und Literaturwissenschaft und an einer ausgewogenen Verbindung von positivistischer Detailforschung und übergreifender Betrachtung. So kann dieser Realienband - auch wegen des von vornherein begrenzten Umfangs - in den darstellenden Teilen nur Skizzen, in den Bibliographien nur eine Auswahl wichtiger Titel bieten.

Der Band ist so angelegt, daß er vor allem das Interesse des Literaturwissenschaftlers auf die Hilfsmittel der beiden anderen Disziplinen lenken soll, die diese für die Erforschung des Singspiels bisher bereitgestellt haben.

Die Literaturwissenschaft selbst hat dem Singspiel bislang wenig Aufmerksamkeit geschenkt. Das entspricht - sieht man von den Ausnahmen der Goethe- und Hofmannsthal-Forschung hier einmal $\mathrm{ab}$ - ihrer Zurückhaltung gegenüber der Gattung Libretto insgesamt. Diese Zurückhaltung dürfte angesichts neuer, z. B. literatursoziologischer Fragestellungen nach den Bedingungen literarischer Produktion und Rezeption und nach der Wirkung und Funktion von Unterhaltungsliteratur nicht mehr angebracht sein.

Der Begriff »Deutsches Singspiel« wird, obwohl er nicht eindeutig ist, beibehalten, seine Problematik im zweiten Abschnitt expliziert.

Frankfurt a. M., im Juli 1974

H.-A. K. 


\section{ABKURZUNGEN}

DLE $=$ Deutsche Literatur in Entwicklungsreihen

DVjs = Deutsche Vierteljahrsschrift für Literaturwissenschaft und Geistesgeschichte

Eitner $=$ R. Eitner: Biographisch-bibliographisches Quellenlexikon der Musiker und Musikgelehrten der christlichen Zeitrechnung bis zur Mitte des 19. Jahrhunderts. 2. Aufl. Bd. I-I I. 1959-60.

$\mathrm{GR}=$ Germanic Review

GRM = Germanisch-romanische Monatsschrift

$\mathrm{JEGPh}=$ Journal of English and Germanic Philology

MGG = Die Musik in Geschichte und Gegenwart. Allgemeine Enzyklopädie der Musik. Hrsg. von F. Blume. Bd. I-Is nebst Suppl. 1949-73.

$\mathrm{ZfdtPh}=$ Zeitschrift für deutsche Philologie 